\title{
MAANVILJELIJÄ- JA PALKANSAAJARUOKAKUNTIEN RAVINTOMENOJEN RIIPPUVUUS ERÄISTÄ TEKIJÖISTÄ
}

\author{
Maire Honkanen \\ Helsingin yliopiston kodin taloustieteen laitos
}

Saapunut 21. 11. 1967

Esillä olevalle tutkimukselle antoi aiheen selvitys, jonka avulla pyrittiin kartuttamaan tietoa siitä, millä tavoin lasten lukumäärän lisäys vaikuttaa perheen ravintobudjettiin. - Meillä on toistaiseksi selvitetty melko vähän kulutusmenojen riippuvuutta eri tekijöistä muiden kuin hintojen ja kuluttajan tulojen funktiona. Tällöin on havaittu, ettei henkeä, kuluttajayksikköä tai esim. ruokakuntaa kohden lasketun kulutuksen vaihteluita tiettynä ajankohtana — jolloin hintojen muutokset eivät vaikuta tuloksiin — voida aina tyydyttävästi selvittää tulojen vaihteluilla.

Viime aikoina onkin kuluttajan käyttäytymistä tutkittaessa kiinnitetty erityistä huomiota itse kuluttajaan liittyviin seikkoihin. Seuraavassa esitettäviin funktioihin on sen vuoksi sisällytetty eräitä muuttujia, jotka kuvaavat tutkimuksen kohteena olevien ruokakuntien ominaisuuksia ja elinolosuhteita. Näiden selvitysten avulla on lähinnä pyritty saamaan viitteitä niistä seikoista, joihin ravintobudjettia lähemmin tarkasteltaessa tämän aineiston puitteissa sekä suunniteltaessa aineiston hankkimista ravintobudjetin analysointia varten esim. kotitalouskirjanpidon avulla, tulee kiinnittää huomiota.

Jäljempänä esitettävien regressioanalyysien aineistona on käytetty maaseudun kulutustutkimusta (SVT XXXII: 24) varten eri osista maata vv. 1959/60 kerättyjä ruokakunnittaisia tietoja ravintomenoista. Aineisto on käsitelty kahtena ryhmänä, joista toisen muodostavat kulutustutkimuksen kohteina olleet 597 viljelijäperhettä, ja toisen 331 maaseudun palkansaajaperhettä. (Syyt ruokakuntien lukumäärien poikkeamiseen maaseudun kulutustutkimuksessa ilmoitetuista lukumääristä on kirjoittaja selvittänyt toisessa yhteydessä, Honkanen 1967 b). Palkansaajaruokakuntia ei aineiston määrän ja hankintatavan (vrt. SVT XXXII: 24) vuoksi ole pyritty jakamaan sosiaaliluokkiin, varsinkin kun melko suurpiirteisellä luokituksella (vrt. SVT XXXII: 24) ei katsottu olevan olennaista merkitystä ruokakunnan 
tulojen (menojen) vaikutuksen ohella. Käytellystä aineistosta johtuen tuloluokan tilalle analyysiin on sisällytetty ruokakunnan kokonaiskulutusmenojen ynnä korkojen ja verojen määrän perusteella laskettu menoluokka. Luokkia on kaikkiaan kymmenen (luokkien rajat on asetettu täysien satojen markkojen kohdalle, jolloin alin luokka on alle $100 \mathrm{mk} / \mathrm{kk}$, ky ja ylin yli $900 \mathrm{mk} / \mathrm{kk}, \mathrm{ky}$ ). Koska a priori oletettiin, etteivät ravintomenot seuraa tulojen (menojen) määrää lineaarisessa suhteessa, funktioon on sisällytetty logaritminen menoluokkatermi. Kun selvitystä jatkettiin lapsiperheiden osalta (HoNkANEN 1967 a), havaittiin ravintomenojen kuitenkin tässä aineistossa muuttuvan lähinnä lineaarisesti kokonaismenojen mukaan. Sen sijaan kaikkien ruokakuntien ravintomenojen vaihteluita heinä-syyskuussa, jolloin ne olivat korkeammat kuin vuoden muina aikoina, kuvasi parhaiten kokonaismenojen logaritminen tai paraabelifunktio (HoNKANEN 1967 b).

Ravintomenoja on tässä yhteydessä käsitelty kaloritarpeen perusteella määritettyä kuluttajayksikköä (SVT XXXII: 24) kohden laskettuina.-Kokonaismenot on sisällytetty funktioon niin ikään ky:ä kohden laskettujen keskimääräisten menojen muodossa. Tiettyyn ajankohtaan liittyvässä aineistossa hintojen vaihtelut näkyvät lähinnä maantieteellisten alueiden puitteissa, mistä syystä funktioon on sisällytetty 0,1 -muuttujina myös ruokakunnan kotipaikan perusteella määräytyvän alueen osoittavat muuttujat (Etelä-Suomi, Sisä-Suomi, Pohjanmaa, Pohjoisja Koillis-Suomi). Koska nyt kysymyksessä olevat tiedot on koottu yhden vuoden aikana (SVT XXXII: 24), hintojen kausivaihtelun esille saamiseksi on tietojen keräämisen ajankohtaan perustuen muodostettu 0,1 -muuttujat (tammi-maaliskuu, huhti-kesäkuu, heinä-syyskuu ja loka-joulukuu). Samaan tapaan on muodostettu muuttujat perheenemännän osallistumisesta ansiotyöhön kodin ulkopuolella (perheenemäntä ei ole ansiotyössä, on osapäivätyössä, tai on kokopäiväansiotyössä). Edelleen on analyysiin sisällytetty kunnan teollistumisastetta (SVT XXXII: 24) osoittavat termit lineaarisessa ja logaritmisessa asteikossa. Muut selittäjät koskevat lähinnä kunkin ruokakunnan demograafisia ominaisuuksia. - Aineiston käsittelyn tietokoneella on tehnyt mahdolliseksi Alli Paasikiven Säätiön kirjoittajalle myöntämä apuraha.

Taulukkoihin 1 ja 2 on poimittu paitsi ravintomenojen yhteismäärän, myös suurimpien tai muusta syystä huomionarvoisten menoryhmien ja yksityisten ruokaainemenojen hajontaa selvittävien regressioanalyysien tulokset. Regressiokertoimien tilastollinen merkitsevyys voidaan todeta esitetyn t- luvun avulla, jolloin vapausasteiden määrä kunkin menoryhmän kohdalla on $(n-1)$ vähennettynä funktioon sisältyvien selittävien tekijöiden lukumäärällä. [Jos t-luku $\geqq 2$, regressiokertoimet poikkeavat $(5 \%$ :n riskin mukaan laskettuna) merkitsevästi O:sta].

Tuloksista voidaan havaita eräitä mielenkiintoisia riippuvuussuhteita menoryhmien ja funktioon sisällytettyjen selittävien tekijöiden kesken. Huolimatta siitä, että menot ovat kuluttajayksikön keskimääräisiä menoja, ruokakunnan ky-määrällä näyttää olleen vaikutusta niiden vaihteluihin. Esim. palkansaajaperheissä voimenot vähenevät kuluttajayksikkömäärän kasvaessa $(b=-0.0273)$. Myös lasten lukumäärän ja eräiden menoryhmien kesken voidaan todeta tilastollisesti merkitseviä riippuvuussuhteita (lasten lukumäärän ja ky-määrän välinen korrelaatio on palkansaajaruokakunnissa 0,67 ja viljelijäruokakunnissa 0,70$)$. Mm. 
viljelijäperheissä maitomenot kuluttajayksikköä kohden laskettuina vähenevät $(\mathrm{b}=-0.367)$ lasten lukumäärän lisääntyessä. Kaloritarpeen perusteella muunnettu henkilöiden määrä ei niin ollen parhaiten sovellu käytettäväksi silloin, kun tarkastellaan ravinnonkulutuksesta aiheutuneita menoja.

Perheenemännän kokopäiväansiotyö on aiheuttanut viljelijäruokakunnissa vähennystä sellaisten raaka-aineiden kuin jauhojen ja suurimoiden käytössä (b = -5.08), mutta sen sijaan lisäystä valmiina ostetun ruoka- ja kahvileivän (viljelijäperheissä $\mathrm{b}=2.36$, ja palkansaajaperheissä $\mathrm{b}=1.59$ ), lihan (ei merkitsevä korrelaatio) ja maanviljelijäruokakunnissa sokerin $(\mathrm{b}=5.25)$ ja makeisten $(\mathrm{b}=1.82)$ kulutuksessa.

Heinä-syyskuussa ravintomenot ovat olleet korkeammat kuin vuoden muina aikoina. Tällöin maanviljelijäruokakunnissa on käytetty runsaasti $\mathrm{mm}$. leipää, voita ja vihanneksia sekä sokeria. Palkansaajaruokakunnissa on käytetty niin ikään runsaasti vihanneksia. Sekä maanviljelijöiden että palkansaajien lihankulutus (= -4.24 ja b $=-2.65)$ sen sijaan on ollut vähäisempää heinä-syyskuussa kuin vuoden muina aikoina. — Eri alueiden ja useiden menoerien välillä voidaan myös havaita merkitseviä vuorosuhteita. Aineiston perusteella ei kuitenkaan voida päätellä aiheutuivatko ne ensi sijassa erilaisista hintasuhteista eri paikkakunnilla vai kulutuksen rakenteessa esiintyvistä eroista.

Hintatietojen puuttuminen aineistosta on mutoinkin rajoittanut eri menojen tarkastelua. Kun esim. kaikki naudanlihamenot on kulutustutkimuksessa esitetty yhtenä lukuna, sen perusteella ei voida päätellä onko ruokakunnassa käytetty vähän ja yksikköhinnaltaan kallista vai runsaasti halpaa naudanlihaa. Taloudellisten näkökohtien huomioon ottamista jo aineiston hankintavaiheessa on siten pidettävä ravintobudjetin yksityiskohtaisen tarkastelun olennaisena edellytyksenä.

\section{Yhteenveto}

Edellä on tarkasteltu ravintomenojen riippuvuutta useista eri tekijöistä regressioanalyysin avulla vv. 1959/60 maaseudun kulutustutkimusta varten kerätyn aineiston perusteella. Tällöin on havaittu mm., ettei kaloritarpeeseen perustuva kuluttajayksikköasteikko parhaiten sovellu käytettäväksi silloin, kun tarkastellaan ravintomenoja. Useiden menoerien on havaittu olevan riippuvuussuhteessa (taul. 1 ja 2) mm. perheenemännän ansiotyössä olemiseen sekä lasten ja kuluttajayksiköiden lukumäärään ruokakunnassa. Samoin esiintyy riippuvuutta joidenkin menoerien ja vuoden eri jaksojen sekä maantieteellisten alueiden kesken. Aineiston ryhmittely eri menoeriin ei kuitenkaan ole suonut mahdollisuuksia mm. yksikköhinnaltaan kalliiden ja suhteellisen halpojen ruoka-aineiden osuuden tarkempaan selvittämiseen ravintobudjetissa. Koska käytettyä aineistoa ei voida pitää koko maaseudun väestöä edustavana, tulosten on lähinnä katsottava antavan viitteitä niistä seikoista, joihin ravintomenojen lähemmässä tarkastelussa tulee kiinnittää huomiota. 


\title{
KIRJALLISUUTTA:
}

Honkanen, M. 1967 a. Lasten lukumäärän vaikutus ravintomenoihin. Summary: The relationship between the number of children and food expenditure. Väestöntutk. vuosik. X-1967-1968. Erip., $21 \mathrm{~s}$.

- 1967 b. The relationship between household consumption expenditure and various factors. Selostus: Kotitalouden kulutusmenojen riippuvuus eri tekijöistä. Maatal.tiet. aikak. 39: 240-255.

Suomen virallinen tilasto (SVT) XXXII: 24. Maaseudun kulutustutkimus.

\section{THE RELATIONSHIP BETWEEN FOOD EXPENDITURE AND VARIOUS FACTORS IN FARMER AND WAGE-EARNER HOUSEHOLDS IN FINLAND}

\author{
Maire Honkanen
}

\author{
Department of Household Economics. University of Helsinki
}

The relationship between food expenditure and several factors has been discussed in the paper, on the basis of regression analysis on the data collected for the 1959/60 rural consumption investigation. It was, for instance, found that the consumer unit scale based on calory requirements is not the most suitable one, when food consumption expenses are studied. It was found that several expense items were related (tables 1 and 2) to e.g. the housewife's paid work outside the home and the number of children and consumer units in the household. Relationships were also found between some expense items, and various times of the year and geographic regions. Classifying the data into various expenditure groups did not, however, make possible further differentiation between high- and low-unit-priced foods in the food budget. Since rural population, the results must only be regarded as indicative of the factors that have to be considered in closer studies of the food expenditure. 
Taulukko 1. Maanviljelijöiden ravintomenojen riippuvuus eri tekijòistä (selittävien muuttujien sarakkeissa kunkin menoerän kohdalla ylimpänä regressiokerroin, sen alapuolella vastaava t-luku ja alimpana korrelaatiokerroin).

\begin{tabular}{|c|c|c|c|c|c|c|c|c|c|}
\hline $\begin{array}{l}\text { Menoerä } \\
\text { Expense item }\end{array}$ & 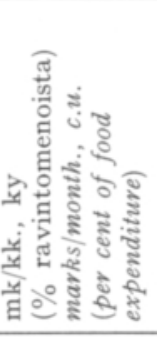 & 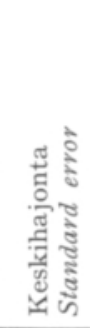 & $\begin{array}{r}\text { Maanti } \\
\text { sij } \\
\text { Geograph }\end{array}$ & $\begin{array}{l}\text { eellinen } \\
\text { nti } \\
\text { location }\end{array}$ & 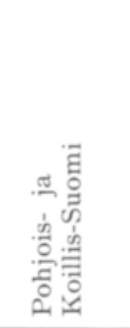 & Tir & $\begin{array}{l}\text { tkimuskau } \\
\text { ajankohta } \\
\text { of study }\end{array}$ & 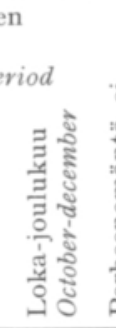 & 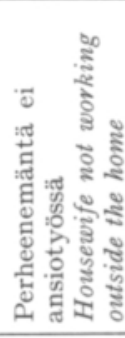 \\
\hline Ravinto yhteensä & 69.23 & 20.23 & & & -4.56 & & 7.15 & & \\
\hline Total food & & & & & 2.54 & & 4.81 & & \\
\hline & & & .10 & .03 & -.14 & -.06 & .11 & .01 & -.04 \\
\hline Jauhot, suurimot & 9.63 & 5.79 & -1.63 & 3.11 & -1.43 & -1.02 & 0.938 & -0.784 & \\
\hline Meal, peeled grains & $(13.9)$ & & 2.16 & 4.25 & 1.81 & 1.58 & 1.47 & 1.21 & \\
\hline $\begin{array}{l}\text { Ruoka- ja kahvileipä } \\
\text { Bread and pastry }\end{array}$ & $\begin{array}{c}1.97 \\
(2.8)\end{array}$ & 2.60 & -.01 & $\begin{array}{r}.16 \\
-1.16 \\
5.13\end{array}$ & -.06 & $\begin{array}{c}-\quad .09 \\
0.663 \\
2.69\end{array}$ & $\begin{array}{l}.10 \\
0.726 \\
3.01\end{array}$ & -.03 & .04 \\
\hline & & & .13 & -.25 & .10 & .05 & .08 & -.06 & -.07 \\
\hline Pehmeä ruisleipä & .44 & .92 & -0.247 & -0.613 & -0.245 & 0.120 & 0.261 & & \\
\hline Soft rye bread & $(0.6)$ & & 2.08 & 5.40 & 1.91 & 1.36 & 3.03 & & \\
\hline & & & -.13 & -.26 & -.04 & .00 & .11 & -.06 & -.01 \\
\hline Maitotaloustuotteet & 22.90 & 7.81 & -2.00 & -1.30 & & -1.12 & 2.47 & & 2.69 \\
\hline Milk products & $(33.1)$ & & 2.48 & 1.75 & & 1.56 & 3.50 & & 1.24 \\
\hline & & & -.03 & -.03 & .01 & -.01 & .08 & .00 & .04 \\
\hline Maito & 13.28 & 5.64 & -2.09 & -2.09 & & 0.775 & 1.08 & & \\
\hline Milk & $(19.1)$ & & 3.85 & 3.89 & & 1.43 & 2.02 & & \\
\hline & & & -.02 & -.12 & .09 & .02 & .03 & .00 & .01 \\
\hline Kerma, juusto & .79 & 1.31 & 0.501 & -0.196 & & 0.147 & 0.265 & & \\
\hline Cream, cheese & (1.1) & & 3.59 & 1.52 & & 1.17 & 2.16 & & \\
\hline & & & .22 & -.15 & -.06 & .00 & .06 & -.00 & -.03 \\
\hline Voi & 8.25 & 3.95 & -0.600 & 0.816 & & & 0.878 & & 2.68 \\
\hline Butter & (11.9) & & 1.60 & 2.18 & & & 2.57 & & 2.40 \\
\hline & & & -.10 & .16 & -.06 & -.06 & .07 & .02 & .07 \\
\hline Margariini & 1.10 & 1.09 & -0.148 & -0.623 & -0.312 & 0.144 & & 0.128 & \\
\hline Margarine & $(1.6)$ & & 1.03 & 4.53 & 2.01 & 1.37 & & 1.21 & \\
\hline & & & .19 & -.23 & -.03 & .03 & -.04 & .06 & -.10 \\
\hline Munat & 1.75 & 2.00 & 1.42 & 0.384 & & 0.580 & 0.580 & -0.261 & \\
\hline Eggs & $(2.5)$ & & 7.79 & 2.13 & & 2.79 & 2.83 & 1.25 & \\
\hline & & & .34 & -.08 & -.16 & .08 & .09 & -.10 & -.02 \\
\hline Liha & 6.98 & 6.84 & & 2.11 & -2.22 & -2.96 & -4.24 & -0.900 & \\
\hline Meat & $(10.1)$ & & & 3.46 & 2.98 & 4.18 & 6.07 & 1.26 & \\
\hline & & & .00 & .22 & -.19 & -.09 & -.21 & .12 & -.04 \\
\hline Lihajalosteet & 2.07 & 2.23 & -0.314 & -1.23 & -0.960 & 0.420 & 0.522 & -0.453 & \\
\hline Meat products & $(3.0)$ & & 1.13 & 4.49 & 3.26 & 1.73 & 2.18 & 1.86 & \\
\hline & & & .17 & -.18 & $-\quad .09$ & .06 & .10 & -.11 & -.02 \\
\hline Kala & 1.93 & 2.68 & -0.580 & & -1.33 & 1.44 & 0.803 & & \\
\hline Fish & $(2.8)$ & & 2.38 & & 4.86 & 5.57 & 3.17 & & \\
\hline & & & .01 & .10 & -.19 & .18 & .05 & -.09 & -.04 \\
\hline
\end{tabular}


Table 1. The relationship between the food expenditure of farmers and various factors (highest in the columns for the independent variables is the regression coefficient, under it the corresponding t-value, and the correlation coefficient, for each expense item).

\begin{tabular}{|c|c|c|c|c|c|c|c|c|c|c|}
\hline 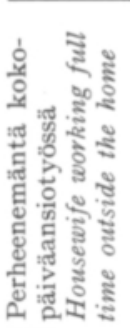 & 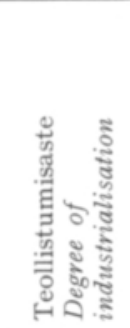 & 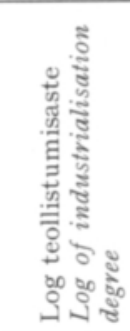 & 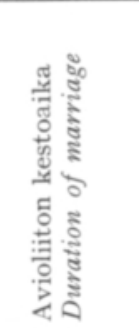 & 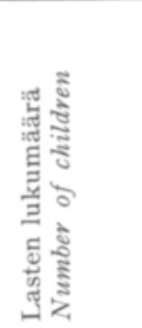 & 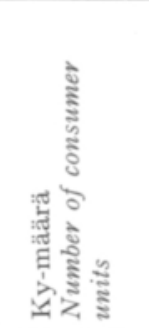 & 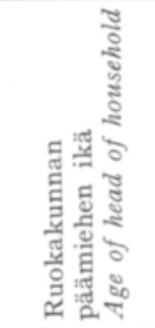 & 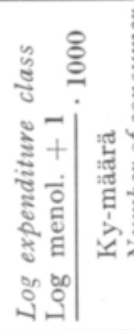 & $\stackrel{\Xi}{\Xi}$ & 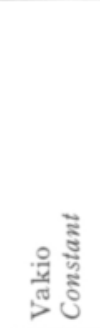 & $\begin{array}{l}\stackrel{\partial}{0} \\
\ddot{*}\end{array}$ \\
\hline & 10.04 & -31.88 & & & & & 75.90 & - & 109.35 & 38,44 \\
\hline & 1.77 & 1.28 & & & & & 18.61 & & & \\
\hline .07 & .01 & .01 & -.03 & -.29 & -.32 & .05 & .59 & & & \\
\hline-5.08 & 0.627 & & 0.192 & & -0.0174 & & 8.66 & - & 14.33 & 9,00 \\
\hline 2.21 & 1.91 & & 1.37 & & 1.17 & & 5.10 & & & \\
\hline-.07 & .07 & .07 & .04 & -.10 & -.07 & .06 & .19 & & & \\
\hline 2.36 & & -1.25 & 0.0972 & 0.0885 & -0.0405 & & & & 3.23 & 13,69 \\
\hline 2.36 & & 2.08 & 1.49 & 1.14 & 5.05 & & & & & \\
\hline .08 & -.17 & -.17 & .04 & -.15 & -.24 & .05 & .16 & & & \\
\hline 0.497 & -0.521 & 1.66 & 0.0294 & & -0.0133 & & -0.641 & & 3.06 & 12,96 \\
\hline 1.39 & 1.61 & 1.19 & 1.35 & & 5.81 & & 2.44 & & & \\
\hline \multirow[t]{3}{*}{.04} & -.17 & -.16 & .05 & -.11 & -.20 & .03 & .04 & & & \\
\hline & 3.61 & -11.80 & & & & & 20.92 & - & 29.48 & 17,64 \\
\hline & 1.41 & 1.08 & & & & & 11.33 & & & \\
\hline \multirow[t]{6}{*}{-.02} & .02 & .01 & -.02 & -.16 & -.20 & .05 & .38 & & & \\
\hline & & & & -0.367 & -0.0240 & 0.240 & 11.07 & - & 10.69 & 10,24 \\
\hline & & & & 2.00 & 1.31 & 1.04 & 6.71 & & & \\
\hline & -.09 & .10 & -.03 & -.08 & -.14 & .03 & .27 & & & \\
\hline & 1.00 & -3.73 & & & & 0.00340 & 2.35 & - & 5.73 & 11,56 \\
\hline & 2.25 & 1.96 & & & & 1.04 & 6.27 & & & \\
\hline \multirow[t]{3}{*}{.03} & -.03 & .04 & .01 & -.14 & -.12 & .05 & .28 & & & \\
\hline & 0.947 & & & -0.0992 & & & 7.76 & - & 13.52 & 15,21 \\
\hline & 4.43 & & & 1.10 & & & 7.20 & & & \\
\hline-.06 & .17 & .16 & -.01 & -.18 & -.17 & .05 & .28 & & & \\
\hline 1.26 & -0.809 & 2.97 & 0.0354 & & -0.00358 & -0.0902 & 0.416 & & 1.59 & 9,61 \\
\hline 2.91 & 2.05 & 1.75 & 1.14 & & 1.28 & 1.88 & 1.30 & & & \\
\hline .13 & -.16 & .14 & .01 & -.05 & -.10 & -.03 & .13 & & & \\
\hline-0.773 & & & -0.0907 & -0.0589 & & & 2.76 & - & 4.30 & 20,25 \\
\hline 1.05 & & & 1.96 & 1.30 & & & 5.14 & & & \\
\hline .00 & -.14 & .11 & -.08 & -.18 & -.19 & .00 & .29 & & & \\
\hline 2.58 & 3.47 & -10.64 & & & & & 11.80 & - & 21.31 & 21,16 \\
\hline 1.03 & 1.55 & 1.10 & & & & & 7.46 & & & \\
\hline \multirow[t]{3}{*}{.07} & .12 & .12 & -.03 & -.14 & -.13 & -.00 & .29 & & & \\
\hline & & & & & -0.00935 & & 2.73 & - & 2.92 & 12,25 \\
\hline & & & & & 1.69 & & 4.32 & & & \\
\hline \multirow[t]{3}{*}{.04} & -.12 & .10 & -.01 & -.15 & -.17 & .01 & .24 & & & \\
\hline & & & 0.0638 & & & & 2.82 & - & 4.74 & 10,24 \\
\hline & & & 1.00 & & & & 4.28 & & & \\
\hline-.01 & .05 & .05 & .02 & -.10 & -.05 & .00 & .14 & & & \\
\hline
\end{tabular}




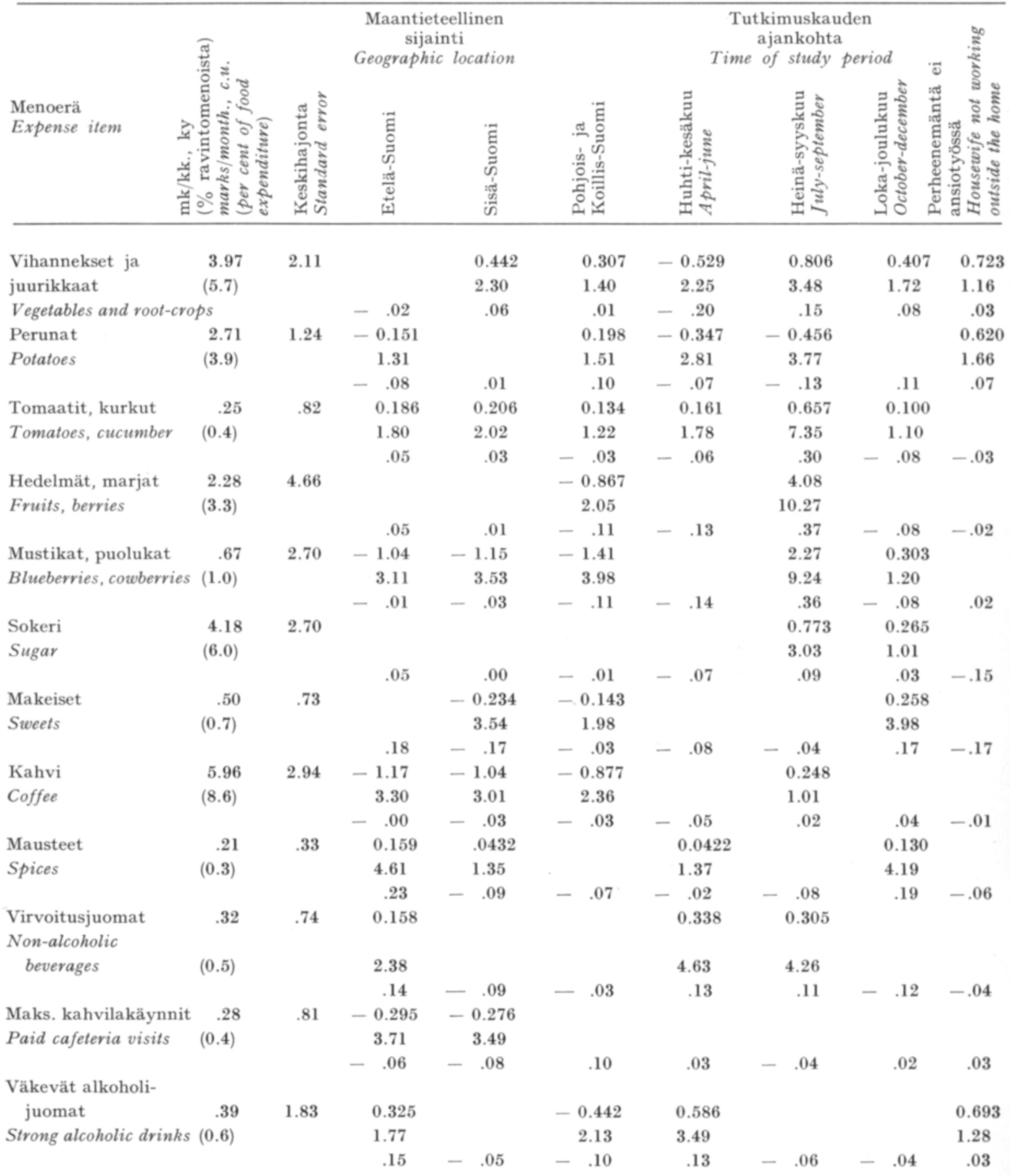


Taulukko 2. Palkansaajien ravintomenojen riippuvuus eri tekijöistä (selittävien muuttujien sarakkeissa kunkin menoerän kohdalla ylimpänä regressiokerroin, sen alapuolella vastaava t-luku ja alimpana korrelaatiokerroin).

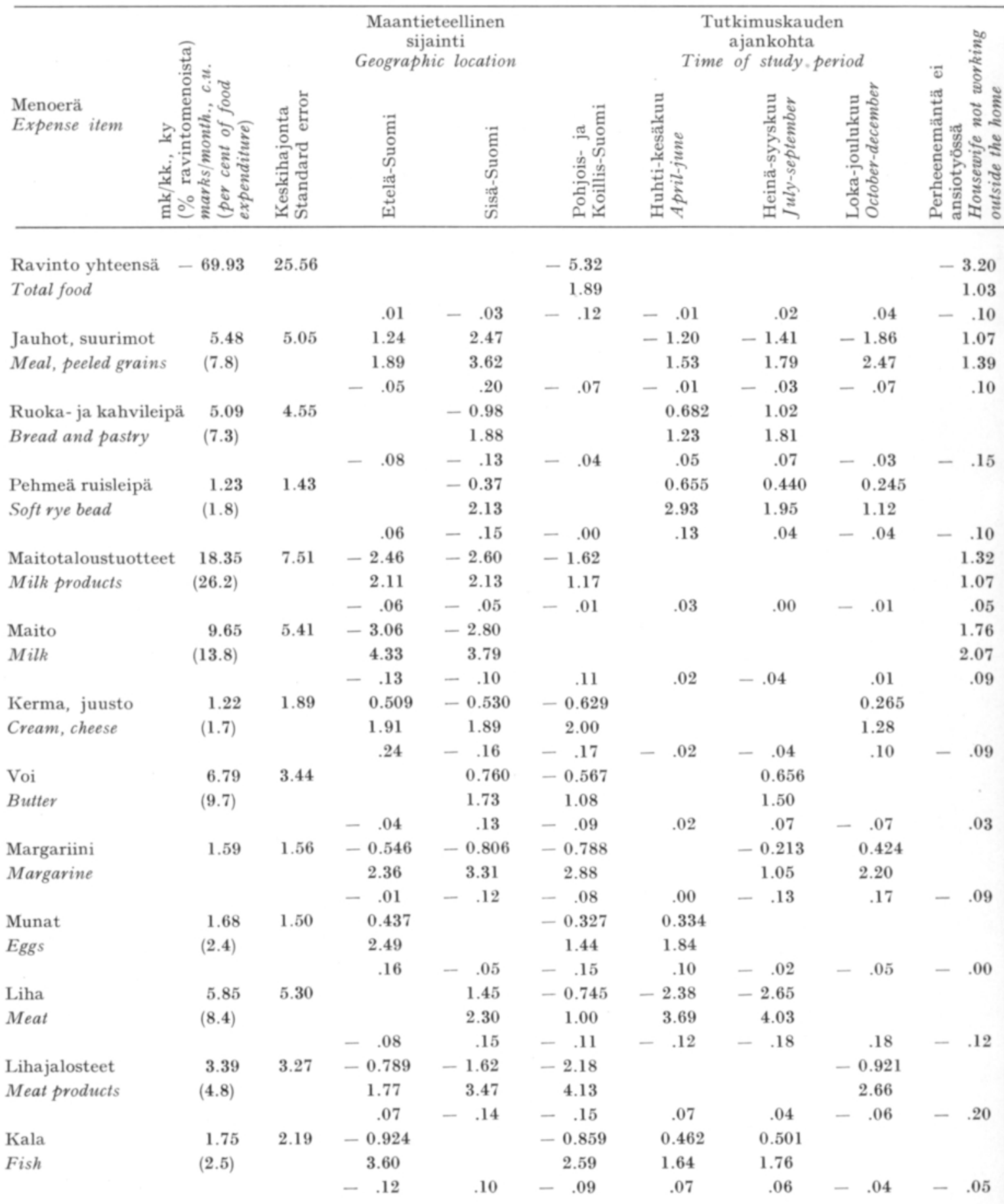


Taulukko 2 jatkuu

Table 2 continues

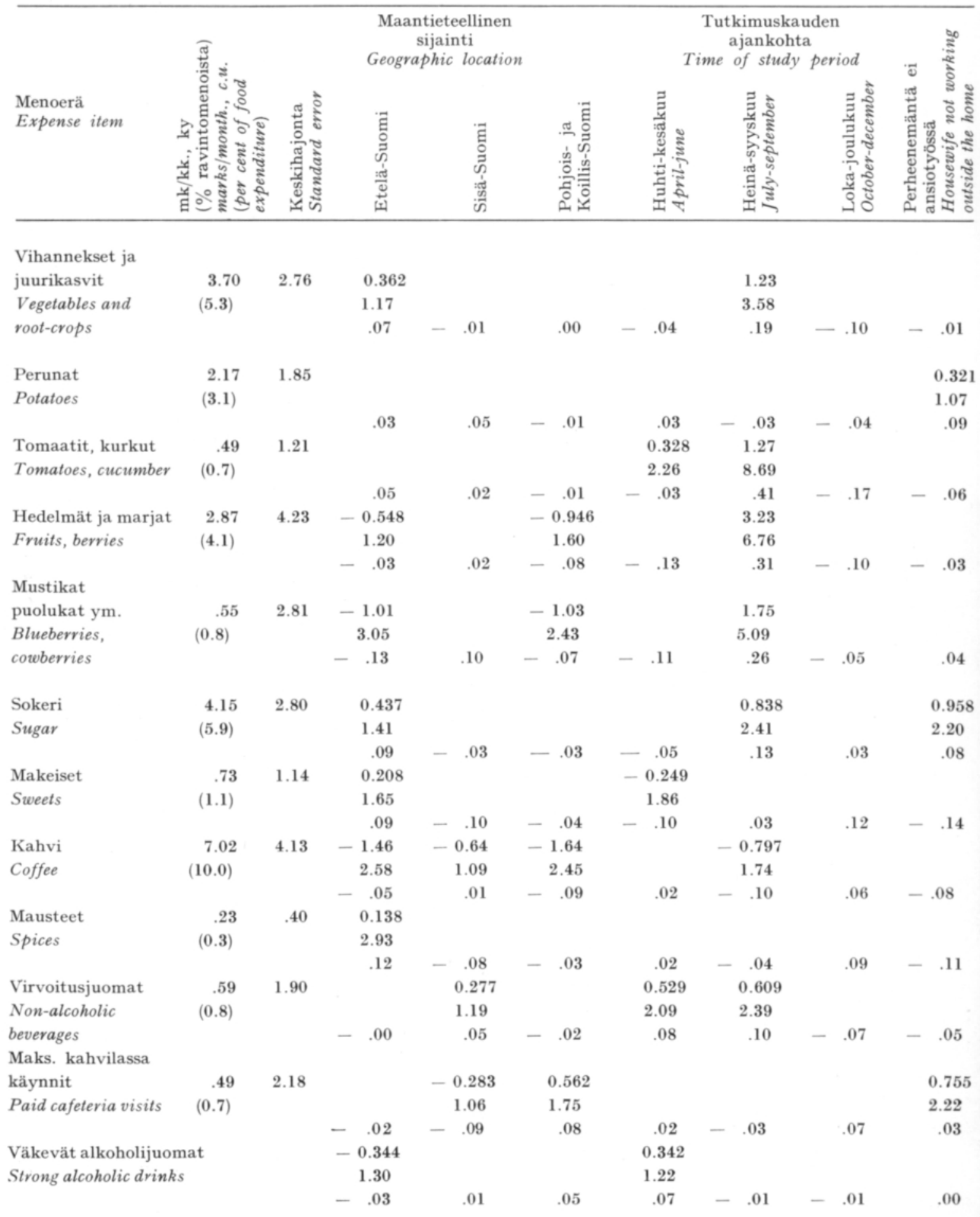


